\title{
Disruptive Low-Carbon Innovations
}

\author{
Author: Charlie Wilson
}

Affiliation: Tyndall Centre for Climate Change Research, University of East Anglia, Norwich, Norfolk NR4 7TJ, UK

Email: charlie.wilson@uea.ac.uk

Phone: +44-1603-591386

\section{Abstract}

This perspective article considers the potential for disruptive innovations to transform the market for energy-related goods and services in line with emission reductions required for stringent mitigation. Its rationale is that consumers are a neglected constituency in societal efforts to meet climate policy objectives. First, I review Christensen's canonical definition of disruptive innovation as low-end products offering novel sources of value to users marginalised or over-supplied by mainstream markets. Second, I apply disruptive innovation concepts to the challenge of climate change mitigation and the necessary contribution of low-carbon innovation. There are both potentials for disruptive lowcarbon innovations but also problems in achieving social benefits through the consumption of private goods. Third, I set out a series of criteria for disruptive low-carbon innovations and apply these to identify sets of potential innovations relating to mobility, buildings \& cities, food, and energy supply. A wide range of consumer-facing innovations offer goods or services with novel attributes currently valued only in small market niches. Fourth, I report on the findings of two workshops on disruptive low-carbon innovation involving innovators, market intermediaries, policymakers and researchers. Different stakeholders hold sharply contrasting understandings of disruptive low-carbon innovation and its distinctive relevance for energy transformation.

\section{Keywords}

disruptive, innovation, climate mitigation

\section{Acronyms}

DLCI disruptive low-carbon innovation

EV electric vehicle

ICE internal combustion engine

ICT information and communication technology

LED light-emitting diode

solar PV solar photovoltaic 


\section{Disruptive innovation}

Personal computing is pervasive. But when first introduced in the late 1970s, the microcomputer performed poorly on all the attributes valued in the mainstream market for computers. The mainstream meant mainframes. Large firms and institutions demanded computers with ever-greater processing speed, storage capacity, reliability, and ever-lower costs per unit of information. Suppliers like IBM competed to service this demand. Relative to mainframes, the newly launched microcomputers were slow, limited, and unreliable. They appeared to offer no competitive threat. But they did offer something wholly new: portability (small volume, lower weight), versatility (ruggedness), low power consumption, and crucially, low unit cost. This value proposition was of no interest to mainstream market demand; but it did entice individuals and small firms as an entirely new segment of users. The rest is history. Steve Jobs and Bill Gates became household names and personal computers permeate daily life.

The microcomputer is used as a classic example of a 'disruptive innovation' by Clayton Christensen in his seminal book, 'The Innovator's Dilemma' (Christensen 1997). Ranked by The Economist as one of the top six best business books ever (The Economist 2011), the Innovator's Dilemma has spawned a mini-industry in management scholarship and practice. Its central argument was that incumbents fail to see disruptive threats from innovations which offer non-mainstream users something wholly new. If successful, disruptive innovations effectively create a new market, a new set of demands and preferences. As a result their transformative potential is huge.

Christensen develops his argument by drawing on a range of innovations that disrupted mainstream goods and services provided by incumbent firms. Examples include: the microcomputer vs. the mainframe; desktop photocopiers vs. giant Xerox copy machines; digital photography vs. film; mobile telephones vs. landline services; small off-road motorcycles (e.g., Honda) vs. large powerful bikes (e.g., Harley); transistors vs. vacuum tubes; discount retailing vs. department stores; drones vs. bombers; Wikipedia vs. Encyclopaedia Britannica; massive open online courses (MOOCs) vs. university degrees; outpatient and in-home clinics vs. general hospitals (Christensen 1997,

Govindarajan and Kopalle 2006b, Christensen et al. 2008, Christensen et al. 2009, Lambert 2014). In each case, the innovations enter the market as 'good enough' alternatives which enfranchise an underserved need or market segment (Christensen et al. 2006).

The application and theorising of Christensen's arguments are principally concerned with firm strategy and performance. Disruptive innovations create asymmetric motivation as incumbent firms move up into higher-end, more profitable segments rather than counter the strategy of disruptive firms entering the market from below. Incumbent firms therefore ignore disruptive innovations and their niche users because of low returns and a lack of necessary internal processes, values or competencies.

But as the story of the microcomputer exemplifies, disruptive innovations also have certain generic characteristics: they offer cheaper, simpler and more versatile alternatives to mainstream goods and services which have become over-specified in meeting many users' needs; they appeal initially to lowend, price-sensitive users or non-users; they underperform on attributes valued by mainstream users, but offer novel attributes or functionality to new users; and they develop in initial market niches until their performance on mainstream attributes improves or mainstream users' preferences shift towards the novel attributes offered (see Table 1).

Christensen also emphasises that the challenge with disruptive innovations is rarely technological but rather about finding a market. Early microcomputers largely used off-the-shelf components put together in a product architecture that was simpler than previous approaches. Incumbent manufacturers did just not anticipate new demand. Ken Olsen, the CEO of Digital Equipment Corp., one of the major players in the US computer industry, pronounced in 1977: "There is no need for any individual to have a computer in their home." 


\section{Disruptive low-carbon innovations}

Low-carbon innovation is integral to research, policy and practice on energy transformation for climate change mitigation. Innovations from solar PV and offshore wind, to smart grids and largescale storage, to electric vehicles and energy-efficient homes are strongly emphasised in modelling studies (Rogelj et al. 2015), mitigation scenarios (Clarke et al. 2014), roadmaps \& strategies (EC 2015, Obama 2017), national climate plans (UK CCC 2017), and R\&D initiatives like Mission2020 (King 2017). The distinguishing feature of these low-carbon innovations is that they offer more efficient or lower carbon substitutes for the incumbent forms of energy production, distribution or use. Rather than improving functionality or offering novel attributes, low-carbon innovations provide the same basic service for end users. As a result they have limited consumer appeal.

Put differently, low-carbon innovations are overwhelmingly sustaining: they improve on existing product or service attributes (Walsh and Linton 2000). This is dichotomous with disruptive: offering novel attributes and so creating a new value proposition. The distinction between sustaining and disruptive innovations (about attributes and users) contrasts with the widely-used typology distinguishing radical and incremental innovations (about technological improvements). Whereas incremental innovations improve cost or performance attributes without altering basic technological designs, radical or breakthrough innovations are discontinuously novel in their design architectures or fundamental technological concepts (Tushman and Anderson 1986). Using solar photovoltaics (PV) as an example, improvements in module efficiency may come from perovskite as a novel material concept (radical) or improved silicon etching techniques (incremental). But neither innovation is disruptive as - for the end user - solar PV continues to improve in cost and performance. In contrast, a business model innovation creating value from decentralised PV and battery storage with digitallyenabled peer-to-peer electricity trading is potentially disruptive as it offers end users new attributes of autonomy and independence (from grids and from utilities) and an active producer-trading role in electricity markets (in lieu of a passive consumer role).

So: what is the microcomputer for climate change? Are there innovations offering novel value to users that could transform the energy system while dramatically reducing emissions? And by strengthening market demand, can disruptive low-carbon innovations engage consumers as an active constituency in mitigation efforts?

Building on Christensen, a working definition of disruptive low-carbon innovation (DLCI) needs to take into account: (1) widespread adoption leading to substantial emission reductions; and (2) critiques and modifications of disruptive innovation concepts since the Innovator's Dilemma, relevant particularly to the digitalisation of traditional energy infrastructure and consumer goods.

\section{Emission reductions \& non-users}

DLCIs must have the potential to reduce greenhouse gas emissions substantially if adopted at scale. This is a marked shift in emphasis from private benefits for consumers (novel attributes and value) to social benefits or public goods (lower emissions). How DLCIs affect energy use and emissions depends not just on the energy-using characteristic of the innovation, but also on what it displaces or substitutes for. As illustrated by the microcomputer in the 1970s, disruptive innovations commonly substitute for non-use. In a global development context, potential consumers excluded from mainstream markets are known as the 'bottom of the pyramid' (Hart and Christensen 2002, Prahalad 2004).

There's a clear tension for DLCIs between low-carbon outcomes and the enfranchisement of nonusers. If 'non-use' is low or zero-emission (e.g., households without cars who walk or cycle), the availability of novel goods and services will not help reduce emissions, even if the innovations themselves are efficient or low carbon. In a development context, moving up the first rung of the energy ladder from traditional fuels (non-commercial biomass) to modern energy resources (grid electricity, solar homes, bottled natural gas, clean cook stoves) is typically net beneficial for emissions, particularly if forest or land clearance is avoided (Johansson et al. 2012). But further up the ladder, particularly in developing country cities, the acquisition of new energy services - cars for mobility, air conditioning for space cooling, meat for nutrition - is typically net detrimental for emissions even if beneficial for material wellbeing and development. 
This raises two issues in the application of disruptive innovation concepts to social benefits such as emission reductions. The low-carbon outcomes of DLCIs depend on: (1) the emissions profile of the incumbent good or service being displaced; and (2) the dynamic background of change in market demand and products, which are themselves shaped by disruptive innovation. This is particularly challenging in a development context in which DLCIs may release latent demand among the underconsuming as incomes rise.

\section{Low-tech vs. high-tech: is Tesla disruptive?}

According to Christensen, incumbents' continuing efforts to improve their goods and services outstrips mainstream users' needs and opens up the lower end of the market to cheaper, simpler alternatives so "normal people can do what only the rich and very skilled could do before" (Lambert 2014).

This prescriptive characteristic of Christensen's disruptive innovation has proved controversial. Is an iPhone or a Tesla Model S disruptive? Tesla in particular has sparked column inches of disagreement. Elon Musk is the poster child of disruption in the energy and automotive industries. Yet Tesla's initial defining electric vehicle, the Model S, retailed at over $\$ 70,000$ in the luxury or sports car niche, and over-performed on conventional vehicle attributes such as speed, acceleration, and features (Christensen 2014). As such, the Tesla Model S was a classic sustaining innovation, offering incrementally better performance at higher price, and competing on a like-for-like basis with the dominant selling (high-end) vehicles in the market (HBR 2015). Indeed Christensen has stated point blank that "Tesla is not disruptive" (Christensen 2014).

That's not to say all electric vehicles (EVs) can't be disruptive ... as long as they are golf carts rather than sports cars. These so-called 'neighbourhood electric vehicles' or NEVs appeal to teenagers in suburbia or the elderly in retirement communities who would otherwise be travelling by transit, the cars of their carers (parents, relatives, friends), or not at all (Lambert 2014). NEVs' disruptiveness comes not from their batteries and electric drive-trains, but from the very different model of urban mobility they offer to currently marginalised transport users: "NEVs could eventually be what PCs were to minicomputers or what desktop copiers were to giant Xerox machines. Starting at the bottom still makes strategic sense" (HBR 2015).

This argument is explicitly rejected by Silicon Valley for whom Tesla is clearly a disruptive threat to the conventional automotive industry. This is evident in how Tesla has integrated advanced information and communication technologies (ICTs) to allow for continuous software-based upgrades to its operating capabilities, while providing new capabilities for both autonomous driving and grid services such as load balancing when recharging (Seba 2014). Although the Model S was clearly highend, Tesla's new release, the Model 3 ("an iPad on wheels"), targets the mass 'mid-size' car market and retails under $\$ 40,000$. This follows the classic trajectory of price-insensitive market niches providing opportunities for learning, improvement, and subsequent migration of cheaper more reliable variants into the mainstream. This is at least one area in which Silicon Valley's take on disruptive innovation coincides with Christensen and indeed many other accounts of innovation and diffusion (e.g., Rogers 2003).

To generalise this counterargument to Christensen, disruption can and does come from above, i.e., superior products which have more capabilities and functionality than what mainstream markets provide, but are also more expensive and so appeal initially only to a high-end market niche. But their cost and performance improvement curves are on a rapid (exponential) trajectory so they rapidly outcompete incumbents. Solar PV and battery technologies (for EVs and distributed storage) are widely-cited current examples of 'exponential technologies' (Seba 2014, Farmer and Lafond 2016); as are a whole host of ICTs relying on sensors, processors, data storage and wireless transmission. The integration of ICTs into traditional energy hardware is opening up possibilities for algorithmic control and automation, distributed (peer-to-peer) networking, and real-time data provision for feedback or machine learning. This is perhaps clearest in the creeping 'smartness' of appliances, homes and grids, as well as in EVs.

It's worth emphasising, however, this form of high-end disruption blurs the distinction between the disruptive - sustaining typology used by Christensen to distinguish innovations in terms of their 
attractiveness to end users, and the radical - incremental dichotomy that characterises the extent of technological advancement or breakthrough.

\section{Characteristics of DLCIs}

Table 1 summarises the characteristics of disruptive innovation and DLCIs from these different perspectives. As well as adding the need for low-carbon outcomes, the working definition of DLCIs proposed in this perspective allows for high-end and/or high-tech sources of disruption in addition to canonical 'bottom-of-the-pyramid' disruption (see column labelled 'this perspective').

Table 1. Characteristics of disruptive low-carbon innovations. (Note: $\sqrt{ } \boldsymbol{V}=$ strongly concerned with; $\checkmark=$ concerned with; $-=$ not concerned with).

\begin{tabular}{|c|c|c|c|c|}
\hline & $\begin{array}{c}\text { Christensen: } \\
\text { disruptive } \\
\text { innovation } \\
\text { a }\end{array}$ & $\begin{array}{c}\text { Silicon } \\
\text { Valley: } \\
\text { disruptive } \\
\text { innovation } \\
\text { b }\end{array}$ & $\begin{array}{c}\text { this } \\
\text { perspective: } \\
\text { disruptive } \\
\text { low-carbon } \\
\text { innovation } \\
\text { (Section } 2)\end{array}$ & $\begin{array}{l}\text { innovator } \\
\text { workshop: } \\
\text { disruptive } \\
\text { low-carbon } \\
\text { innovation } \\
\text { (Section 4) }\end{array}$ \\
\hline novel application of knowledge (i.e., innovation) & $\sqrt{ }$ & $\sqrt{ }$ & $\sqrt{ }$ & $\sqrt{ }$ \\
\hline initially attractive in a market niche then performance improves & $\sqrt{ } \sqrt{ }$ & $\sqrt{ }$ & $\sqrt{ }$ & $\sqrt{ }$ \\
\hline disrupts mainstream firms, markets or regulatory frameworks & $\sqrt{ } \sqrt{ }$ & $\sqrt{ }$ & - & - \\
\hline combines technological \& business model innovation to create value & $\sqrt{ }$ & $\sqrt{ }$ & $\checkmark$ & $\checkmark$ \\
\hline offers novel product or service attributes to users & $\sqrt{ }$ & $\sqrt{ }$ & $\sqrt{ }$ & - \\
\hline appeals to low-end market \& price-sensitive users or non-users & $\sqrt{ } \sqrt{ }$ & - & $\sqrt{ }$ & - \\
\hline simple, low-tech alternatives to over-performing mainstream goods & $\sqrt{ }$ & - & $\sqrt{ }$ & - \\
\hline appeals to high-end market \& price-insensitive technophile users & - & $\sqrt{ }$ & $\sqrt{ }$ & - \\
\hline radical technological breakthroughs which improve exponentially & - & $\sqrt{ }$ & $\checkmark$ & - \\
\hline reduces greenhouse gas emissions if adopted at scale & - & - & $\sqrt{ }$ & $\checkmark$ \\
\hline requires supportive policy or regulatory environment & - & - & - & $\sqrt{ } \mathbf{V}$ \\
\hline
\end{tabular}

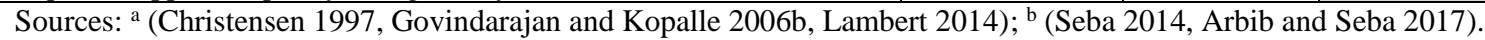

\section{Examples of disruptive low-carbon innovations}

By its nature disruptiveness is hard to identify ex ante (Govindarajan and Kopalle 2006b, Govindarajan and Kopalle 2006a). However the characteristics of disruptive innovation and DLCIs summarised in Table 1 provide selection criteria for scanning innovations at the current fringes of mainstream markets. Surveys of potentially disruptive innovations identify low-cost manufactures challenging over-specified mainstream products in markets as diverse as harbour cranes, X-ray equipment, supercomputers, container ships, cars, consumer electronics, pianos, microchips and water purifiers (Zeng and Williamson 2007, Tyfield and Jin 2010, Hang et al. 2015).

Tyfield and Jin (2010) is one of the few studies specifically to identify disruptive low-carbon innovations. They focus on China, and identify seven potentially disruptive technologies (and their sponsoring firms): e-bikes (by Luyuan); solar thermal water tanks (by Himin Group); anaerobic biogas digesters and slurry for organic agriculture (by GEI Lijang Snow Mountain Biogas Project); biomass pellets from agricultural residues (by Shengchang Biomass); low-tech AC and solar desalination (by ISAW); hydrogen fuel cells for generators, specialised vehicles, hand-held power sources (by Pearl Hydrogen); high-efficiency water purification for industrial processes (by ZNHK Sin-entech). Tyfield and Jin (2010) estimate the combined emission reduction potential of these seven DLCIs at $0.3 \mathrm{GtCO}_{2}$ per year, equal to approximately 3\% of China's emissions in 2010 (based on data from the Global Carbon Atlas). Hang et al. (2015) also identify e-bikes in China (by Luyuan) as well as wind turbines in India (by Suzlon) with DLCI characteristics. These examples vary in emphasising low-cost alternatives to mainstream products (e.g., wind turbines), or emphasising novel performance attributes for users marginalised from mainstream markets (e.g., e-bikes).

Alongside these few surveys of DLCIs, there are numerous market surveys of new 'game-changing', 'breakthrough', or 'disruptive' technologies for energy transformation (McKinsey 2012, McKinsey 2013, New Scientist 2016). As an example, McKinsey (2012) identify ten innovations which are 'disrupting' or will 'disrupt' energy productivity, focusing on the US: unconventional natural gas production; EVs; advanced ICEs; solar PV; LED lighting; grid-scale storage (batteries, flywheels, and 
ultracapacitors); digital transformers (for large-scale high-voltage power conversion); compressor-less air-conditioning and electro-chromic windows; clean coal (cheap carbon capture and storage); biofuels and electrofuels (cellulosic and algal-based biofuels). Despite the potential impacts of these technological advances on existing businesses and forms of energy production, it is again unclear what novel attributes are offered to users, collapsing the distinction between disruptiveness (about markets and users) and radicalness (about technological improvements).

\section{Survey of DLCIs}

For this perspective article, recent grey literature on low-carbon innovation was surveyed using the characteristics of DLCIs set out in Table 1 as well as specific mentions of 'disruptiveness' or 'disruption'. The survey covered over a hundred sources from sectoral and economy-wide reports to modelling and scenario studies, innovation case studies, and synoptic views of energy innovation, including: McKinsey Global Institute, Energy = Innovation (McKinsey 2012); New Scientist, Gamechanger (New Scientist 2016); McKinsey Global Institute, Disruptive Technologies (McKinsey 2013); UK Government, 8 Great Technologies (HMG 2013); Mission Innovation, Clean Energy R\&D Focus Areas (King 2017); The Global Energy Assessment (Johansson et al. 2012); Energy \& Climate Change Committee of the UK House of Commons, The Energy Revolution (House of Commons 2016); Tony Seba, Clean Disruption (Seba 2014); Rethinx, The Disruption of Transportation (Arbib and Seba 2017).

The literature survey identified potential DLCIs in four domains: mobility; buildings \& cities; food; and energy supply \& distribution. Given the tendency noted above for market surveys to focus on technological advances, particular emphasis was placed on novel attributes for consumers or energy end-users. This excluded any upstream supply-side innovations (e.g., offshore wind and large-scale grid storage providing electricity which is a homogeneous product for end users). An attribute common to all the DLCIs is their emission-reducing potential.

Using mobility as an example, Table 2 lists potential DLCIs identified along with the incumbent form of mobility which they generally displace. It's important to note that some of these innovations were cited as disruptive in the literature but would have been excluded had the criteria for DLCIs in Table 1 been strictly applied. This includes all the alternative fuel vehicles offering substitute forms of private motorised mobility (i.e., fuel-efficient, biofuel and hydrogen fuel cell vehicles, and potentially also EVs as discussed earlier). This definitional confusion is considered further in Section 4.

The DLCIs in Table 2 are grouped into four: alternative vehicle technologies substituting for the internal combustion engine (ICE); alternative forms of auto-mobility displacing car ownership and use; alternatives to auto-mobility displacing car use altogether; and reducing mobility demand. There are many other strategies and approaches to reducing mobility-related emissions that do not fall under the definition of DLCIs. These include urban planning, compact cities, car-free communities, shifts from motorised modes to public transport or active modes (walking, cycling), and 'disappearing traffic' - the removal of road infrastructure and restoration of car-free urban environments (e.g., express freeways in Seoul, South Korea).

Table 2. Potentially disruptive low-carbon innovations (DLCIs) relating to mobility.

\begin{tabular}{|l|l|l|}
\hline \multirow{2}{*}{$\begin{array}{l}\text { type of innovation } \\
\text { or strategy }\end{array}$} & $\begin{array}{l}\text { potentially disruptive low carbon } \\
\text { innovations (DLCIs) }\end{array}$ & displaced incumbent \\
\hline \multirow{4}{*}{$\begin{array}{l}\text { alternative fuel or } \\
\text { vehicle technology }\end{array}$} & electric vehicles (EVs) & internal combustion engine (ICE) vehicles \\
\cline { 2 - 3 } & fuel efficient ICEs & ICE vehicles \\
\cline { 2 - 3 } & hydrogen fuel cell vehicles & ICE vehicles \\
\cline { 2 - 3 } $\begin{array}{l}\text { alternative form } \\
\text { of auto-mobility }\end{array}$ & advanced biofuels & ICE vehicles \\
\cline { 2 - 3 } & autonomous (self-driving) vehicles & ICE vehicles \\
\cline { 2 - 3 } & mobility-as-a-service (MaaS) ${ }^{\text {a }}$ & car ownership \& use \\
\cline { 2 - 3 } $\begin{array}{l}\text { alternative to } \\
\text { auto-mobility }\end{array}$ & ride-sharing & car ownership \& use \\
\hline \multirow{2}{*}{$\begin{array}{l}\text { reduced demand } \\
\text { for mobility }\end{array}$} & e-bikes & car ownership \& use \\
\cline { 2 - 3 } & neighbourhood EVs & bikes, motorbikes, cars \\
\cline { 2 - 3 } & telecommuting, video- or teleconferencing & commuting \\
\hline
\end{tabular}


Notes: a mobility-as-a-service (also inter-modality) refers to integrated scheduling, booking and payment systems for multiple transport modes (ride-sharing, bus, train) through a single gateway or account (typically via a mobile app); ${ }^{b}$ interactive virtual reality can be used for immersive interaction by remote (e.g., currently used in medical diagnosis or surgery).

Mobility-related examples of DLCIs include car sharing, e-bikes, and mobility-as-a-service (Table 2). In terms of novel attributes for end users, these innovations perform poorly on valued mainstream attributes associated with car ownership. However they offer something new and different: service use, choice variety, no (or low) maintenance responsibilities.

Although not analysed here in detail, the same broadly holds for DLCIs identified in other domains. Examples of DLCIs relating to buildings \& cities include internet of things, net zero energy homes, and distributed PV-storage systems. These innovations perform poorly on valued mainstream attributes such as low upfront cost, low user involvement (passive consumption), and provision by centralised networks or utilities. However they offer novel attributes to end users including control, active involvement, and autonomy.

Examples of DLCIs relating to food include urban and community-based growing, reduced food waste schemes, and modular hydroponic and aquaponic systems. These innovations perform poorly on valued mainstream attributes such as year-round availability, low user involvement, and standardisation (at centralised retailers). However, they offer novel attributes to end users including social networks, active involvement, and visibility (localisation).

Examples of DLCIs relating to energy supply \& distribution include peer-to-peer trading, vehicle-togrid, and community or district energy networks. These innovations perform poorly on valued mainstream attributes such as low user involvement (passive consumption), time-invariant costs, and dependence on external systems of provision. However, they offer novel attributes to end users including active involvement ('prosumption'), functional diversity, and network interactions.

These are clearly very broad-brushed examples of how the novel attributes of DLCIs for different energy end-uses contrast with mainstream valued attributes. As few of these DLCIs are simply substitute products, it is not easy to delineate neatly the attributes or characteristics that appeal to end users. Nor are the emission-reduction potentials of many of these DLCIs clear. As noted earlier, the impact of widespread adoption of DLCIs on emissions depends on what is displaced, by whom, and against what dynamic background context of technological change.

\section{How do low-carbon innovators understand disruptive innovation?}

Table 1 includes a final column summarising the understanding of disruptive low-carbon innovation expressed by participants of two back-to-back workshops held in London in March 2017. The workshops explored the potential contribution of disruptive innovation to reducing carbon emissions. They were organised by Future Earth and the Tyndall Centre for Climate Change Research, with financial support from the UK Science \& Innovation Network. An initial 'innovator' workshop focused on low-carbon innovations and markets, bringing together firms, investors, market intermediaries, and policymakers in different domains including mobility, cities and energy supply. A second 'researcher' workshop focused on research needs and challenges, bringing together thinkers and researchers working on low-carbon disruption, system transformation and innovation, particularly in the energy domain. Full details of the workshop participants, talks, roundtable sessions, and discussions are available in a detailed report (Wilson 2017) available for download here: http://silci.org/key-insights-from-workshops-on-disruptive-low-carbon-innovations/

Key findings are summarised below. Short-hand labels of 'innovators' and 'researchers' are used to describe participants in the first and second workshops respectively even though the composition of workshop participants was more diverse.

\section{Meanings and understandings of DLCI}

The two workshops took markedly different perspectives on disruptive innovation and its applicability for pressing energy-transformation challenges. For innovators, the distinctiveness of disruptive lowcarbon innovation was not at all clear. Disruption was seen as an inherent characteristic or 
consequence of innovation in general (see 'innovator workshop' column in Table 1). Innovators articulated very few clear elements of disruptive innovation, and implicitly rejected Christensen's definition.

In contrast, for researchers disruptive innovation was clearly a contested concept. Many definitional questions were raised about the relationship between disruptive innovation and incremental, gamechanging, transitional, and transformational innovation. Some argued that generalising a definition of disruptive innovation was neither appropriate nor meaningful as disruptiveness varied in different contexts in terms of what was being disrupted, over what timescales, and how. For researchers, disruption was also primarily understood in terms of system transformation (although to some extent this was pre-conditioned by the disciplinary backgrounds of participants and the under-representation of business and marketing scholars). From a systems perspective, sociotechnical transition processes drive or open up space for disruptive innovation rather than the other way round. Placing system transformation centre stage shifts the focus away from a narrow technical framing of the problem which DLCI is generally interpreted as trying to solve.

In sum, the two workshops revealed no common understanding of DLCI, neither among innovators for whom it was indistinguishable from any other form of low-carbon innovation, nor among researchers for whom it was largely reframed as a challenge of systemic transformation. This was an important insight (returned to further below), but also one which unwound the unifying thread between the two workshops.

\section{Unresolved tensions for DLCIs and their relevance for energy transformation}

Beyond these definitional issues, the two workshops covered many other topics on DLCI spanning actors and institutions, incumbents, markets and users, education and communication, and the requisite roles of finance, policy and governance more broadly. These topics are reported and discussed in detail in the full workshop report (Wilson 2017).

Here, the focus is on drawing out unresolved tensions from the workshop discussions. These tensions bubbled below a surface of broad agreement on the challenges for and importance of DLCI, revealing both ambiguity and confusion on the perceived relevance of DLCIs for energy transformation.

Are consumers a help or a hindrance for DLCI?

According to Christensen, disruptive innovation is predicated on latent consumer demand for novel goods and services (see 'Christensen' column in Table 1). Innovators certainly identified the opportunities for novel business-to-consumer (B2C) value propositions to open up new markets. Specific early-adopting niches were identified as viable targets, with diffusion through these earlyadopter networks potentially accelerated by social influence effects in an increasingly fragmented media space.

However, the public writ large was also strongly characterised as an inert incumbent force resisting change. Many workshop participants noted that DLCIs face strong social resistance as they are 'painful' in imposing transitional or switching costs on the 'painless' continuation of current practices. The innovator workshop saw this in terms of trust, fear, and public misconceptions. The researcher workshop was interested in the underlying dynamics that generated this social resistance, linked to aspirational lifestyles and product ownership. Disruption implies risk and a potentially uneven distribution of benefits and costs. Adverse social consequences of disruption may be strongly felt in communities that 'lose' out as the relative strength of different economic sectors shifts.

\section{Should knowledge on DLCI be shared?}

According to Christensen, returns on disruptive innovation are captured by the disruptors at the expense of incumbents. In contrast, one of the most common observations during the innovator workshop was that knowledge sharing among networks of innovation actors was essential. 'Frictionfree coordination' and a stronger consensus around the value of network-building help support DLCI.

However, innovators also argued that various forces necessarily worked against knowledge sharing. These included a lack of incentives, and the complexity and diversity of inter-relationships between innovation actors. Intellectual property protection is a double-edged sword for DLCI. Open source 
business models facilitate innovation and knowledge exchange, but potentially undermine innovators' ability to appropriate the returns on their innovation investments.

\section{Are market forces enough for DLCI?}

According to Christensen, disruptive innovation is generated and selected by market adoption environments (see 'Christensen' column in Table 1). But from workshop discussions on DLCIs, market forces alone are clearly not enough. New strategies and policies were considered essential for opening up markets to DLCIs, with innovators and governments needing to develop stronger reciprocal relationships characterised by trust, substantive expertise, advanced signalling of intentions, and clear enforcement.

However, workshop participants also recognised that market forces had driven the rapid cost and performance improvements in technologies such as solar PV and EVs which underpin their disruptive potential. Reliable projections of market potentials for such DLCIs also makes them bankable, and exerts a pull on supporting regulation.

An obvious if bland resolution of this tension is that market forces are necessary but not sufficient for DLCIs, with the requirement for emission-reducing outcomes driving a wedge between disruptive innovations and disruptive low-carbon innovations with respect to market forces and policy.

Another related issue noted by workshop participants is that investors, insurers and financial intermediaries are all important market actors for DLCI. Finance can pressure incumbents to adapt. Whether through external pressure to address climate risks or internal corporate social responsibility initiatives, it is in the economic self-interest of major companies to recognise the threat climate change poses to business as usual. However, investors were seen as lacking relevant expertise and appropriate risk-return criteria to assess disruptive innovation. Dedicated, flexible financing for DLCI was also lacking, particularly for small firms and entrepreneurs developing and trialling new business models.

\section{Should policy support DLCI?}

Christensen is almost entirely silent on the role of policymakers and regulators in supporting or responding to disruptive innovation (see 'Christensen' column in Table 1). In contrast, policies, funding, and governance strategies for DLCIs dominated discussions throughout the innovator workshop. Some participants called for dirigiste planning (e.g., energy efficiency as a strategic infrastructure issue) or for a clear industrial strategy to help innovations bridge the 'valley of death' between R\&D and market diffusion. Others called for less regulation to create space for more private investment. Either way, investors in DLCI need certainty. Policies should be flexible but credible. Prescriptive policy erodes flexibility in meeting defined targets and adaptability to changing market conditions; but abrupt policy changes are damaging (as with recent UK examples in residential energy efficiency and feed-in tariffs for solar PV).

None of this is specific to disruptive low-carbon innovation, revealing again the lack of any coherent interpretation of the term. If 'disruptive' had been removed from the workshop title, facilitation and framing talks, almost all the discussions on policy would still have been pertinent. Views expressed were anchored on participants' first-hand knowledge and experience of what works for low-carbon innovation (and what doesn't work). This anchoring was particularly evident in discussions of policy specifics. 'All policies listed here' was the second most voted on idea \& insight from the workshops, referring to the dozens of specific policy suggestions collated. Policy instruments called for by participants spanned both technology-push (e.g., R\&D funding, demonstrators, standards) and marketpull (e.g., carbon pricing, subsidies, public procurement, personal carbon allowances, transparent emissions reporting). Amid this general discussion, only two policy ideas stood out as being specifically concerned with disruptive low-carbon innovation. First, the regulatory requirement for cost-benefit analysis was seen as blocking disruptive innovation unless it could take option values into account (keeping open future possibilities). Second, policies forcing combinatorial innovation were seen as enhancing DLCI value propositions (e.g., all autonomous vehicles must be zero carbon).

Both workshops were posed the more fundamental question: is it appropriate for policy to provide open and direct support for disruptive innovation? Neither workshop provided any real answer. 
Overall, this adds up to a scattergun position of innovators towards public policy: support disruption vs. maintain stability; comprehensive policy mixes vs. market forces; adaptability vs. durability (particularly for investors); collaboration vs. protecting intellectual property; industrial strategy vs. not picking winners. These unresolved tensions again reveal the lack of clarity about the distinctive meaning or implications of disruptive low-carbon innovation, and its relevance for rapid energy transformation.

\section{Discussion}

A wide range of goods and services offer both novel value propositions for consumers and the potential to reduce emissions by displacing energy-intensive incumbents. These potential DLCIs are at the current fringes of mainstream markets. Some but not all meet the selection criteria for DLCIs expanded from Christensen's original definition and adapted to include the social benefits of widespread adoption (see Table 1). Others lack clearly identifiable business models and rely either on behavioural change or mainstream consumer preferences. The interpretation of DLCIs is clearly contested and important definitional uncertainties remain.

This final discussion identifies salient issues identified in the literature review (Section 1-2), innovation surveys (Section 3) and DLCI workshops (Section 4) which determine the relevance and usefulness of disruptive innovation to energy transformation for climate change mitigation.

\section{Disruptive vs. breakthrough}

Loosening Christensen's restrictive definition allows disruption from above by high-tech high-spec products which improve in performance and fall in cost so dramatically that they move mainstream (Section 2). Despite the potential impacts of these technological advances on existing businesses, it is unclear what novel attributes are offered to users. This blurs the distinction between the user and market-focused challenge of disruptive innovations (and their sustaining opposites) and the technological breakthrough-focused challenge of radical innovations (and their incremental opposites). This blurring was clearly apparent in the innovator workshop (Section 4) as well as in the market survey of potential DLCIs with its emphasis on cutting-edge technologies from hydrogen fuel cells and electric vehicles to smart grids and precision agriculture (Section 3).

Further evidence of the conflation between technology challenges (e.g., EVs) and user and market challenges (e.g., car-sharing) was provided by a short survey of innovation experts participating in the two workshops described in Section 4. Prior to the workshops, participants self-identifying as experts on mobility were asked to rank the innovations listed in Table 2 on two seven point scales: potential disruptiveness $(+3=$ potentially very disruptive, $-3=$ potentially not disruptive at all); and potential emission reductions $(+3=$ large reduction in emissions, $-3=$ large increase in emissions). Figure 1 plots the mean scores on potential disruptiveness (y-axis) and potential impact on GHG emissions (xaxis). The innovations are clustered in the top right of the Figure 1 plot as they were selected based on the criteria for DLCIs.

This is a very small sample size $(n=13)$ and provides illustrative results only. According to experts, the DLCIs towards the top right corner of the Figure 1 plots are the most promising in being both potentially disruptive and potentially emission-reducing. The top three are: mobility-as-a-service, electric vehicles (EVs), car-sharing (or car clubs). This is a mix of novel technology (EVs), novel business models for creating value from existing infrastructures (mobility-as-a-service), and distinctive value propositions challenging prevailing mobility norms (car-sharing). 
Figure 1. Rankings of mobility-related innovations from survey of workshop participants.

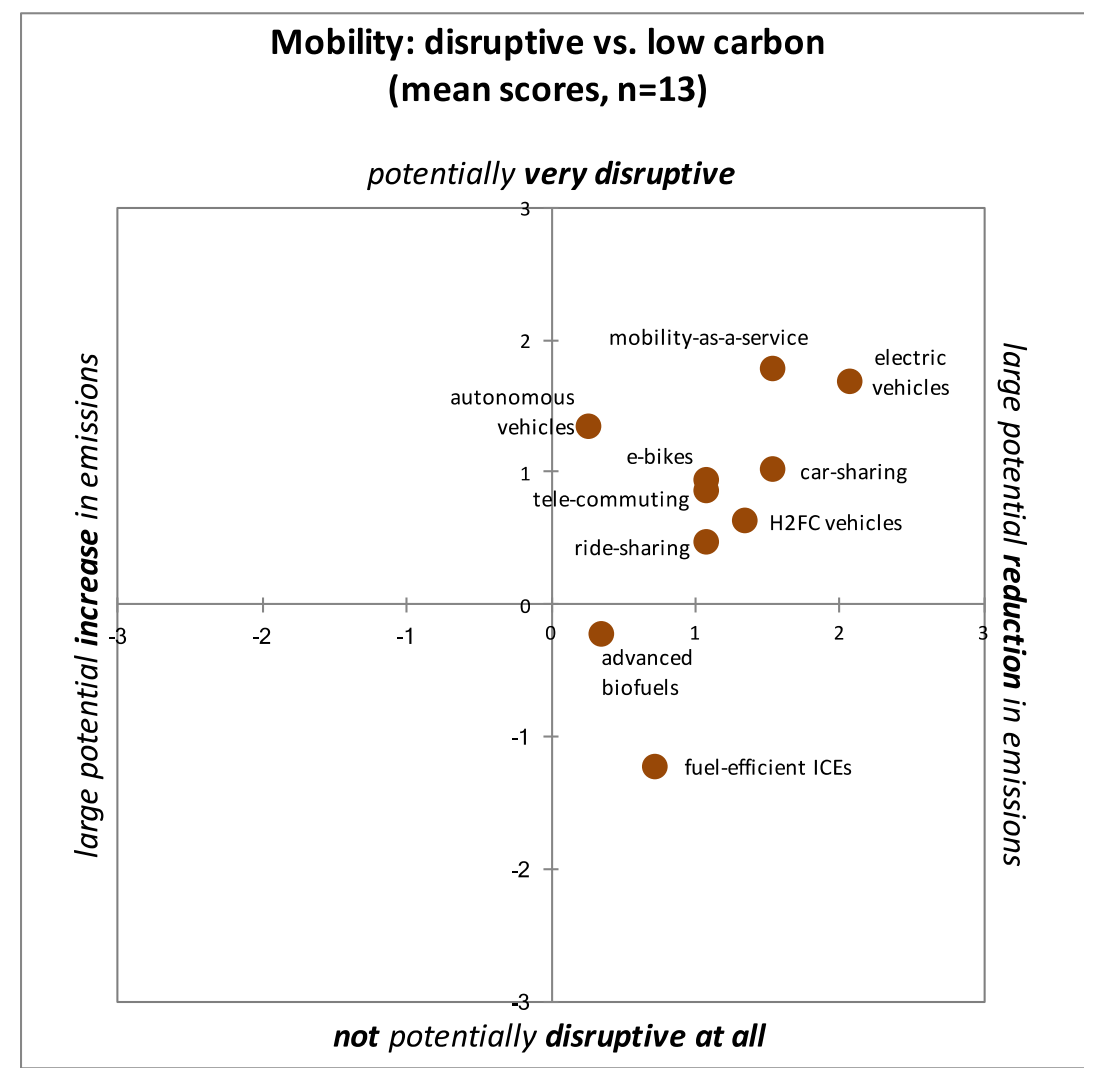

\section{Granularity}

Christensen's examples of disruptive innovations tend to be more distributed, accessible, small-scale, shareable, and extendable or replicable at low marginal cost relative to the incumbents they displace (Section 1). In other words, disruptive innovations tend to offer user-scaled alternatives to large-scale, infrastructure-dependent, centrally-provided goods and services. In a low-carbon context, this points towards a 'granular' distributed energy transformation involving end users in multiple domains and services from heating and eating to moving and making.

Notwithstanding the general tendency for discussions during the innovator workshop to ignore or diverge from Christensen's arguments (Section 4), this is one specific area of convergence. Small-scale DLCIs with clear value propositions were identified by innovators as facing lower barriers to market. Short lead times and rapid learning cycles associated with modular innovations improve the feasibility of scaling up to meet market demand.

Conversely, DLCIs with 'no room to fail' face additional barriers which discourage risk-taking experimentation. Yet it is precisely these large-scale DLCIs which tend to dominate market surveys (Section 3): large-scale grid storage, digital transformers for high-voltage power conversion, carbon capture and storage, and algal-based biofuels (McKinsey 2012). Upstream utility-scale decarbonisation of electricity and liquid fuels is also at the heart of long-term climate change mitigation scenarios (Clarke et al. 2014).

\section{Definitional ambiguity}

The composition of the innovator workshop was broad, ranging from start-ups and innovation facilitators to incumbents and policymakers. Neither the innovator nor the researcher workshop was designed to reach consensus on the interpretation and implications of DLCI. Nevertheless, there were numerous unresolved tensions in the workshop discussions (Section 4). Mostly these tensions arose from the overlay of low-carbon outcomes (social benefits) on disruptive innovation concepts (private goods). Are consumers a hindrance? Should knowledge be openly shared? Are market forces insufficient? Are clear and stable policy frameworks essential? From a canonical disruptive innovation 
perspective, each of these is answered with a resounding 'no!'. From a disruptive low-carbon innovation perspective, each has an equivocal 'probably' or a clear 'yes'.

Further tensions were identified in the characteristics of DLCIs as defined in this perspective article (Section 2) as well as in the examples of potential DLCIs identified in the literature (Section 3). Requiring a low-carbon outcome from disruptive innovation creates a problematic tension for novel goods and services which enfranchise the 'bottom-of-the-pyramid' by displacing low or zero-emission alternatives, even if these are associated with poverty and exclusion from fossil-fuelled modern life. At best this implies a trade off between the welfare-enhancing and emission-reducing outcomes of DLCI adoption. This is analogous to the 'rebound effect' through which more efficient and so cheaper energy services induce higher consumption. Introducing non-users to mainstream markets also requires quantification of emission-reduction potentials against a dynamic background of rising incomes and development. DLCI may only be a useful lens for examining novel goods and services in mature markets where displaced incumbents are more energy or carbon-intensive.

\section{Are Christensen's ideas relevant for DLCI?}

Neither innovators nor researchers 'bought into' Christensen's focus on novel attributes for end users marginalised from mainstream markets (Section 4), nor formally recognised his definition and examples of disruptive innovation (Section 1). The "Tesla is not disruptive" argument prompted outright incredulity among some innovators at the workshop, just as it has in Silicon Valley (Section 2). There were many more specific areas of disagreement expressed during the innovator workshop. New policies and regulatory frameworks were seen as essential for opening up markets to DLCIs, rather than being largely incidental. Consumers were seen as resistant to change, rather than being active pursuers of novelty and so willing participants in disruption. Additionally, incumbent firms were seen as benefiting from low marginal cost production from depreciated assets, and strong relationships with policymakers and regulators. This made it costly to integrate DLCIs into existing markets and infrastructures, in stark contrast to Christensen's view of how disruptive innovations undercut incumbents' strategic focus on moving upmarket.

Nevertheless, there were some areas in which Christensen's arguments were implicitly accepted by workshop participants. First, there was recognition that DLCIs were generated by a diversity of innovators and competences, typically from outside mainstream markets. Cities in particular were identified as incubators and test beds for DLCIs. Second, there was clear agreement that DLCIs must be designed and marketed to serve users' needs, emphasising improved quality of life (or from an emission-reduction perspective, 'co-benefits'). Third, the importance of business models for unlocking value was firmly and frequently expressed. Circular economies and sharing economies were cited as generic types of business model for disruptive innovation, although many others have been identified in relevant literature (e.g., Burger and Luke 2017). These emphases on clear value propositions and innovative business models chime with Christensen's challenge for disruptive innovation as being about finding users and markets. However, discussions on business models also tended to circle around the importance of supportive policy environments to enable innovators to capture economic value from the public good characteristics of low-carbon innovations.

\section{Conclusions}

Transforming the energy system to mitigate climate change is an enormous challenge. It requires directed, aligned and consistent efforts to innovate more sustainable ways of producing, distributing and using energy and materials (Wilson and Grubler 2014). Consumers are the elephant in the room, a neglected constituency in societal efforts to meet international and national climate policy objectives. Escaping 'carbon lock-in' by vested interests in a fossil fuel-rich energy system is another oftdiscussed challenge (Unruh 2002).

Disruptive innovation is a field of business and management scholarship interested in the transformative potential of novel goods and services for consumers. Its outcome is the dislodging of incumbent firms and interests from entrenched market positions.

Exploring the applicability of disruptive innovation to energy transformation is relevant, timely, important, but still poorly understood. Certain inherent characteristics of disruptive innovation undermine low-carbon outcomes. Definitional ambiguities and interpretations undermine clear 
propositions and consensus. A market-oriented focus of disruptive innovation morphs into a policyoriented focus of disruptive low-carbon innovation. These unresolved tensions and conceptual indecisions open up a clear need for attention, study and debate on what DLCI actually is or could be, and hence its potential and potentially unique contribution to energy transformation.

\section{Acknowledgements}

This work was supported by ERC Starting Grant \#678799 for the SILCI project (Social Influence and disruptive Low Carbon Innovation). Funding for the innovator and researcher workshops was from the UK Science \& Innovation Network through Future Earth and the Tyndall Centre for Climate Change Research. David Tyfield provided helpful comments on an earlier draft.

\section{References}

Arbib, J. and T. Seba (2017). Rethinking Transportation 2020-2030: The Disruption of Transportation and the Collapse of the Internal-Combustion Vehicle and Oil Industries. RethinkX Sector Disruption Reports. California, US, RethinkX.

Burger, S. P. and M. Luke (2017). "Business models for distributed energy resources: A review and empirical analysis." Energy Policy 109: 230-248.

Christensen, C. (2014). "Tesla is Not Disruptive and Other Corrections." Bloomberg https://www.bloomberg.com/news/articles/2014-12-04/innovators-dilemma-clayton-christensen-ontruly-disruptive-ideas.

Christensen, C., J. Grossman and J. Hwang (2009). The Innovator's Prescription: A Disruptive Solution for Health Care, New York McGraw-Hill Books.

Christensen, C. M. (1997). The Innovator's Dilemma. New York, HarperBusiness.

Christensen, C. M., H. Baumann, R. Ruggles and T. M. Sadtler (2006). "Disruptive innovation for social change." Harvard business review 84(12): 94.

Christensen, C. M., M. B. Horn and C. W. Johnson (2008). Disrupting class: How disruptive innovation will change the way the world learns, McGraw-Hill New York.

Clarke, L., K. Jiang, K. Akimoto, M. Babiker, G. Blanford, K. Fisher-Vanden, J.-C. Hourcade, V. Krey, E. Kriegler, A. Löschel, D. McCollum, S. Paltsev, S. Rose, P. R. Shukla, M. Tavoni, B. v. d. Zwaan and D. P. v. Vuuren (2014). Chapter 6: Assessing Transformation Pathways. Working Group III contribution to the IPCC 5th Assessment Report, Climate Change 2014: Mitigation of Climate Change. Cambridge, UK and New York, NY, USA, Cambridge University Press.

EC (2015). Communication from the Commission C(2015) 6317 final. Towards an Integrated Strategic Energy Technology (SET) Plan: Accelerating the European Energy System Transformation. Brussels, Belgium, European Commission (EC).

Farmer, J. D. and F. Lafond (2016). "How predictable is technological progress?" Research Policy 45(3): 647665.

Govindarajan, V. and P. K. Kopalle (2006a). "Disruptiveness of innovations: measurement and an assessment of reliability and validity." Strategic Management Journal 27(2): 189-199.

Govindarajan, V. and P. K. Kopalle (2006b). "The Usefulness of Measuring Disruptiveness of Innovations Ex Post in Making Ex Ante Predictions." Journal of Product Innovation Management 23(1): 12-18.

Hang, C. C., E. Garnsey and Y. Ruan (2015). "Opportunities for disruption." Technovation 39-40: 83-93.

Hart, S. L. and C. M. Christensen (2002). "The Great Leap: Driving Innovation From the Base of the Pyramid." MIT Sloan Management Review 44(1): 51-56.

HBR (2015). "Tesla's Not as Disruptive as You Might Think." Harvard Business Review May 2015: 22-23. HMG (2013). 8 Great Technologies. London, UK, HM Government.

House of Commons (2016). The energy revolution and future challenges for UK energy and climate change policy: Third Report of Session 2016-17. London, UK, Energy and Climate Change Committee, House of Commons.

Johansson, T. B., N. Nakicenovic, A. Patwardhan and L. Gomez-Echeverri (2012). Global Energy Assessment: Towards a Sustainable Future. Cambridge, UK, Cambridge University Press.

King, D. (2017). "Global Clean Energy in 2017." Science 355(6321): 111.

Lambert, C. (2014). Disruptive Genius. Harvard Magazine. July-August 2014: 38-43.

McKinsey (2012). Energy = innovation: 10 disruptive technologies. McKinsey on Sustainability \& Resource Productivity, McKinsey Global Institute. 1: 10-15. 
McKinsey (2013). Disruptive technologies: Advances that will transform life, business, and the global economy, McKinsey Global Institute.

New Scientist (2016). Gamechangers: Energy. London, UK, New Scientist.

Obama, B. (2017). "The irreversible momentum of clean energy." Science 355(6321): 126.

Prahalad, C. K. (2004). The Fortune at the Bottom of Pyramid. Philadelphia, PA, Wharton School Publishing. Rogelj, J., G. Luderer, R. C. Pietzcker, E. Kriegler, M. Schaeffer, V. Krey and K. Riahi (2015). "Energy system transformations for limiting end-of-century warming to below 1.5 [deg]C." Nature Clim. Change 5(6): 519-527. Rogers, E. M. (2003). Diffusion of Innovations. New York, Free Press.

Seba, T. (2014). Clean disruption of energy and transportation. Silicon Valley, CA, Clean Planet Ventures. The Economist (2011). Business books: Aiming High. The Economist. London, UK.

Tushman, M. L. and P. Anderson (1986). "Technological Discontinuities and Organizational Environments." Administrative Science Quarterly 31(3): 439-465.

Tyfield, D. and J. Jin (2010). "Low-carbon disruptive innovation in China." Journal of Knowledge-based Innovation in China 2(3): 269-282.

UK CCC (2017). Meeting Carbon Budgets: Closing the policy gap. London, UK, UK Committee on Climate Change.

Unruh, G. C. (2002). "Escaping carbon lock-in." Energy Policy 30(4): 317-325.

Walsh, S. T. and J. D. Linton (2000). "Infrastructure for Emergent Industries Based on Discontinuous Innovations." Engineering Management Journal 12(2): 23-31.

Wilson, C. (2017). Disruptive Low Carbon Innovation Workshops: Synthesis Report. Norwich, UK, Tyndall Centre for Climate Change \& Future Earth.

Wilson, C. and A. Grubler (2014). Lessons Learnt from the Energy Technology Innovation System. Energy

Technology Innovation: Learning from Historical Successes and Failures. A. Grubler and C. Wilson. Cambridge, UK, Cambridge University Press: 349-370.

Zeng, M. and P. Williamson (2007). Dragons at Your Door: How Chinese Cost Innovation Is Disrupting Global Competition. Cambridge, MA, Harvard Business School Press. 